\title{
Investigation of AIGaN buffer layers on sapphire grown by MOVPE
}

Philipp van Gemmern

Yilmaz Dikme

Necmi Biyikli

Holger Kalisch

Ekmel Ozbay

Rolf $\mathrm{H}$. Jansen

Michael Heuken 


\title{
Investigation of AlGaN buffer layers on sapphire grown by MOVPE
}

\author{
P. van Gemmern ${ }^{a}$, Y. Dikme ${ }^{a}$, N. Biyikli ${ }^{b}$, H. Kalisch ${ }^{a}$, E. Özbay $^{b}$, R. H. Jansen ${ }^{a}$, \\ and M. Heuken ${ }^{c, d}$ \\ ${ }^{a}$ Institut für Theoretische Elektrotechnik, RWTH Aachen, Kopernikusstraße 16, \\ D-52074 Aachen, Germany \\ ${ }^{b}$ Department of Physics, Bilkent University, Bilkent, Ankara 06800, Turkey \\ ${ }^{c}$ AIXTRON AG, Kackertstraße 15-17, D-52072, Aachen, Germany \\ ${ }^{d}$ Institut für Halbleitertechnik, RWTH Aachen, Sommerfeldstraße 24, D-52074 Aachen, \\ Germany
}

\begin{abstract}
In this work, AlGaN layers were grown on sapphire by metal-organic vapor phase epitaxy (MOVPE) on (0001)oriented sapphire substrates, with the intention to investigate the effect of varying $\mathrm{Al} / \mathrm{MO}$ and $\mathrm{V} / \mathrm{III}$ ratios on the $\mathrm{Al}$ incorporation into the AlGaN layers. The parameters $\mathrm{Al} / \mathrm{MO}$ and $\mathrm{V} / \mathrm{III}$ describe the proportions of source material inside the reactor. With the help of optical transmission measurements, characteristic cut-off wavelengths of the $\mathrm{Al}_{x} \mathrm{Ga}_{(1-x)} \mathrm{N}$ layers were determined. These wavelengths were used to calculate the $\mathrm{Al}$ content $\mathrm{x}$ of the layers, leading to values between $26.6 \%$ and $52.1 \%$. Using the two process parameters $\mathrm{Al} / \mathrm{MO}$ and $\mathrm{V} / \mathrm{III}$ as input and the $\mathrm{Al}$ content of the $\mathrm{AlGaN}$ layers as a response variable, the experimental results were further investigated with the help of the software STATGRAPHICS. An estimated response surface for the variable $\mathrm{x}$ was generated. It was found that the $\mathrm{Al}$ incorporation is only tunable within a wide range for high $\mathrm{V} / \mathrm{III}$ ratios of about 900. For constant $\mathrm{Al} / \mathrm{MO}$ ratios and varying $\mathrm{V} / \mathrm{III}$ ratios, two different growth characteristics were observed at high and low $\mathrm{Al} / \mathrm{MO}$ values. This behavior is ascribed to the superposition of two oppositional effects.
\end{abstract}

Keywords: AlGaN, MOVPE, sapphire, V/III ratio, Al/MO ratio

\section{INTRODUCTION}

The GaN-based material system and its devices have gained much attention for electronic applications due to their outstanding electrical properties such as high breakdown voltages, high peak electron velocities and high sheet electron concentrations, especially in two-dimensional electron gas structures. Due to their direct bandgap at room temperature, the group III nitrides offer numerous advantages in regards to optoelectronic devices as well, like blue, near-ultraviolet and violet light emitting diodes (LEDs) and laser diodes (LDs). ${ }^{1}$ In the current focus of device research are solar-blind AlGaN-based photoconductors and Schottky barrier photodiodes. ${ }^{2-6}$ Ternary alloys such as $\mathrm{Al}_{x} \mathrm{Ga}_{(1-x)} \mathrm{N}$ can be used to tailor the electronic and optical properties of these semiconductors. The bandgap of AlGaN depends on the aluminium concentration and is therefore tunable from $3.4 \mathrm{eV}$ to $6.2 \mathrm{eV}$, for $\mathrm{x}=0$ and $\mathrm{x}=1$, respectively. Despite its attractive properties, there have been relatively few publications on the properties of this alloy system. In addition to that, the majority of these papers are dedicated to studies on the characteristics of compounds having $\mathrm{x}$ values below $20 \%$. Only few researchers studied the growth of AlGaN epitaxial layers having a high $\mathrm{Al}$ mole fraction. ${ }^{7}$ This work is about the epitaxy of AlGaN layers on (0001)oriented sapphire substrates. Several growth experiments were conducted with varying process parameters. The intention was to investigate the effect of these variations on the $\mathrm{Al}$ incorporation into the deposited AlGaN layers. 


\section{EXPERIMENTAL}

All samples were grown in AIXTRON MOVPE reactors on 2-inch double-side-polished, (0001)-oriented $\mathrm{Al}_{2} \mathrm{O}_{3}$ substrates. Trimethylgallium (TMGa), trimethylaluminium (TMAl), and ammonia $\left(\mathrm{NH}_{3}\right)$ were used as precursors, $\mathrm{H}_{2}$ and $\mathrm{N}_{2}$ as carrier gases. As a first step of each growth process, before the epitaxial deposition was initiated, a desorption routine was implemented. The susceptor temperature was ramped up to $1100{ }^{\circ} \mathrm{C}$ while the pressure was reduced to $20 \mathrm{hPa}$. During this procedure, the carrier gas is set to hydrogen. At these conditions, volatile organic impurities desorb from the wafer surface. Another effect of this process step is the evaporation of oxygen atoms from the $\mathrm{Al}_{2} \mathrm{O}_{3}$ crystal, leaving behind aluminium atoms with dangling bonds, which can afterwards assist the formation of AlN without an additional Al precursor. To conduct this so-called nitration, the ammonia source was opened for one minute after reducing the susceptor temperature to $850{ }^{\circ} \mathrm{C}$ for the nucleation step. Only after the nitration, TMAl was supplied. A low-temperature (LT) AlN nucleation layer with a thickness of $12 \mathrm{~nm}$ was deposited at a pressure of $200 \mathrm{hPa}$, followed by $200 \mathrm{~nm}$ high-temperature (HT) AlN grown at $1195{ }^{\circ} \mathrm{C}$ and a pressure of $50 \mathrm{hPa}$. A second LT AlN interlayer of $22 \mathrm{~nm}$ was deposited at the same temperature and pressure like the nucleation layer. The process temperature for the final AlGaN layer was $1195{ }^{\circ} \mathrm{C}$, the reactor pressure was $50 \mathrm{hPa}$. Figure 1 illustrates the employed layer sequence.

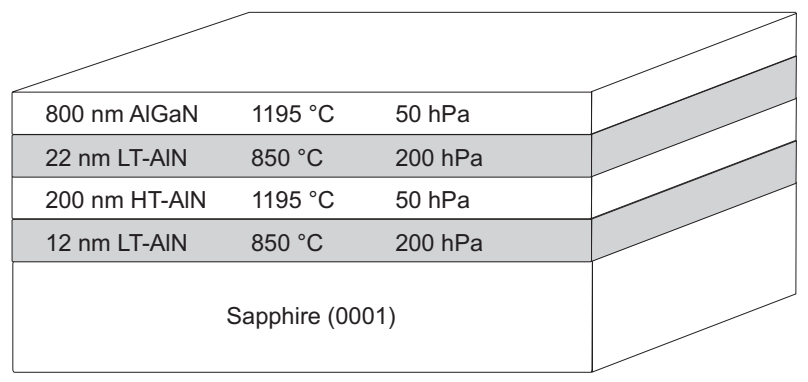

Figure 1. Sequence and thickness of epitaxially grown layers with process temperatures and pressures.

For all runs, the total flow through the reactor was kept constant at $6000 \mathrm{ml} / \mathrm{h}$, whereby the $\mathrm{MO}$ and the hydride inlet each accounted for half of the flow. The ammonia flow was varied between $500 \mathrm{ml} / \mathrm{h}$ and $900 \mathrm{ml} / \mathrm{h}$, the TMGa flow between $2 \mathrm{ml} / \mathrm{h}$ and $4 \mathrm{ml} / \mathrm{h}$ and the TMAl flow between $21 \mathrm{ml} / \mathrm{h}$ and $46 \mathrm{ml} / \mathrm{h}$ for the AlGaN growth of the diverse samples.

The influence of the epitaxial parameters $\mathrm{V} / \mathrm{III}$ ratio and $\mathrm{Al} / \mathrm{MO}$ ratio was investigated in this study. The $\mathrm{V} / \mathrm{III}$ ratio describes the relation of partial pressures of group $\mathrm{V}$ to group III precursors inside the reactor chamber. The $\mathrm{Al} / \mathrm{MO}$ ratio represents the relation of the TMAl partial pressure to the sum of partial pressures of all metal-organic group III precursors. Partial pressures are taken as a measure for the quantity of source materials available to the epitaxial growth process. In the scope of the experiments, the V/III ratio was varied between 440 and 869 , the $\mathrm{Al} / \mathrm{MO}$ ratio between 0.44 and 0.82 .

The cut-off wavelength of the samples, above which light is transmitted and below which light is absorbed by the AlGaN layer, was obtained by UV optical transmission measurements in the spectral range from $200 \mathrm{~nm}$ to $500 \mathrm{~nm}$. An Ocean Optics CHEM2000-UV-VIS spectrophotometer was used for the measurements. The output of a deuterium-tungsten light source was coupled into a multi-mode solarization-resistant optical fiber which illuminated the samples. The transmitted light was conducted by another optical fiber to the spectrometer (PC2000-UV-VIS PC Plug-in Fiber Optic Spectrometer) that operates in the $200 \mathrm{~nm}$ to $850 \mathrm{~nm}$ wavelength region.

\section{RESULTS AND DISCUSSION}

\subsection{The epitaxial growth process}

Due to the nature of the transmission spectroscopy, the AlGaN layers to be investigated had to have the lowest bandgap energies among all other layers that were deposited on the sapphire substrates. Out of the white 
light that was used for the transmission measurements, photons are absorbed if their energy is higher than the bandgap energy of the material they pass. For this reason, no GaN nucleation layer could be used for these experiments, and for the same reason no HT GaN layers could be deposited nor any AlGaN layers with a lower Al mole fraction than the one to be investigated.

Usually, if GaN is epitaxially grown on sapphire substrates, a growth temperature for the AlN nucleation layer of around $550{ }^{\circ} \mathrm{C}$ is used to achieve high crystalline quality. For the epitaxy of HT AlN, the temperature for the AlN nucleation layer has to be increased to about $850^{\circ} \mathrm{C}$. That means the growth temperature of the AlN nucleation layer on sapphire depends on the material that is to be deposited afterwards. $\mathrm{Here}_{\mathrm{Al}} \mathrm{Al}_{x} \mathrm{Ga}_{(1-x)} \mathrm{N}$ with variable $\mathrm{x}$ values had to be grown and because of this, the reactor temperature for the deposition of the nucleation layer would have had to be varied between $550{ }^{\circ} \mathrm{C}$ and $850{ }^{\circ} \mathrm{C}$, according to the Al content of the AlGaN layer. To exclude any effect of different AlN nucleation temperatures on the $\mathrm{Al}$ incorporation in the $\mathrm{Al}_{x} \mathrm{Ga}_{(1-x)} \mathrm{N}$ layers, an universal nucleation procedure was developed. A structure with two LT AlN layers was chosen (Fig. 1) to make the nucleation layer growth temperature independent of the $\mathrm{Al}$ content of the AlGaN layer. By growing HT AlN after the first LT AlN layer, a fixed growth temperature of $850{ }^{\circ} \mathrm{C}$ for the nucleation layers of all samples could be used. The second LT AlN layer decouples the AlGaN from the HT AlN. The deposition temperature of the second LT AIN is independent of the subsequently grown material, the above mentioned temperature adaption is only important for LT AlN layers directly deposited on the sapphire substrate.

\subsection{In-situ reflectance measurements}

The growth process was monitored by in-situ reflectance spectroscopy. The reactor is equipped with a model F30 reflectometer by Filmetrics Inc., which uses a white-light source and a photodiode that operates at a wavelength of $601.5 \mathrm{~nm}$. The left part of Figure 2 shows the reflectivity measurement as well as the reactor temperature for the growth process. The HT AIN oscillations are saturated from the beginning, indicating a two-dimensional growth mode, which is typical for the epitaxy of AlN. The subsequent AlGaN growth oscillations show increasing amplitudes before they pass to saturation. The average reflectivity of the AlGaN growth oscillations remains constant, which reveals a high material quality. Minor fluctuations of the amplitude are caused by temperature variations of the measuring device.

Out of the reflectance oscillations, growth rates between $300 \mathrm{~nm} \cdot \mathrm{h}^{-1}$ and $1100 \mathrm{~nm} \cdot \mathrm{h}^{-1}$ were determined.
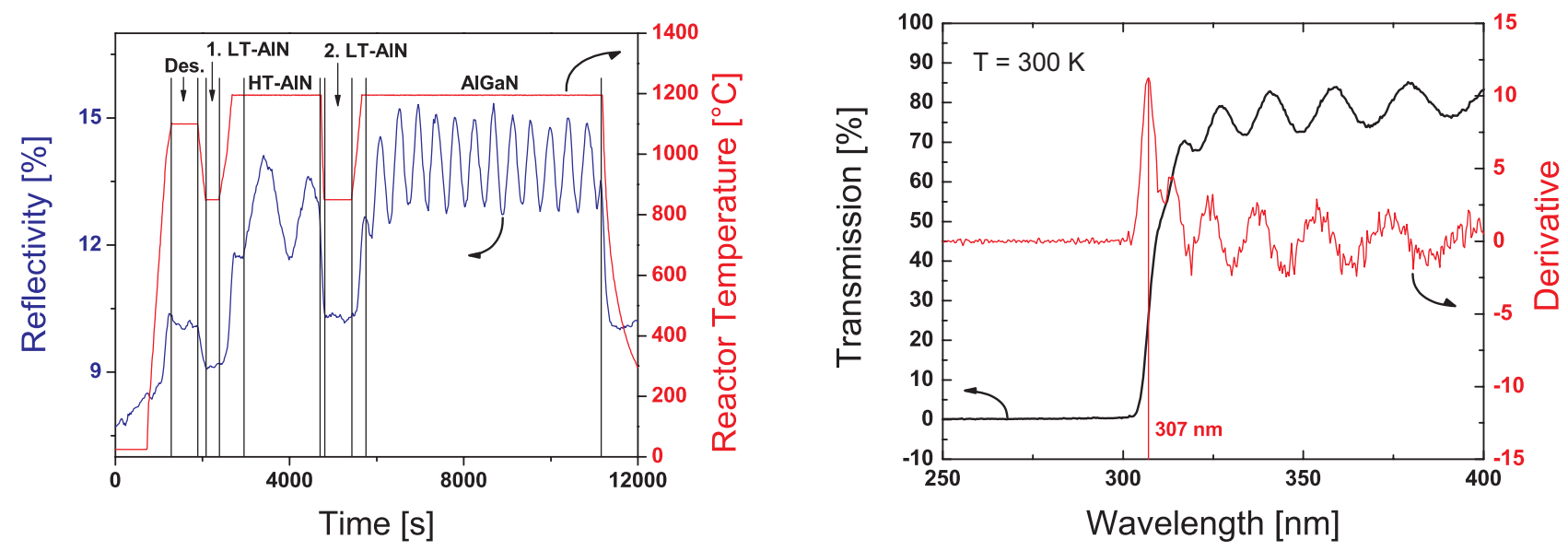

Figure 2. Reflectance measurement taken during the growth process at a wavelength of $601.5 \mathrm{~nm}$ (left) and transmission spectrum of an AlGaN layer on sapphire including the first derivative of the transmitted intensity (right). 


\subsection{Transmission spectroscopy}

As mentioned before, transmission measurements were conducted to determine the aluminium content of the samples. The right part of Figure 2 shows a transmission measurement of a typical sample. A clear descent of the intensity can be observed in the transmission spectra. The large period modulation that shows in the transmitting part of the spectrum is caused by interference effects within the various layers of the samples.

No fixed definition for the localization of the cut-off wavelength exists. Though being relatively sharp, the decline of the transmitted intensity is not confined to one single wavelength, but is spread within a range of a few nanometers. Because of this, its arbitrary determination out of the transmission spectrum possesses a certain inaccuracy. As a standardization for this experimental series, the first derivative of the transmission curve was generated and the cut-off wavelength was read out at the position of the leftmost peak in the derivative curve, which is illustrated in Figure 2. Thereby, the magnitude of the derivative function reflects the abruptness of the transition from transmitted to absorbed wavelengths. In this way, cut-off wavelengths ranging from $269 \mathrm{~nm}$ to $314 \mathrm{~nm}$ were obtained. Cut-off wavelengths below $280 \mathrm{~nm}$ are required for solar-blind devices, which corresponds to $\mathrm{Al}$ concentrations above $45 \%$.

\subsection{Investigation of experimental results}

Out of the cut-off wavelengths, the actual bandgaps of the AlGaN layers were calculated, which in turn were employed to determine the aluminium contents. The simple quadratic dependence for ternary alloys as given in Ref. 8 was transformed accordingly. A room-temperature bandgap energy for GaN of $3.40 \mathrm{eV}$ and for AlN of 6.20 $\mathrm{eV}$ were assumed here, as well as a bowing parameter of $\mathrm{b}=1.0$, following the recommendation of Vurgaftman et al. in Ref. 8. In this way, aluminium concentrations in the AlGaN layers between 26.6\% and $52.1 \%$ were obtained.

The $\mathrm{V} / \mathrm{III}$ and $\mathrm{Al} / \mathrm{MO}$ ratios were taken as input parameters, the $\mathrm{Al}$ incorporation into the AlGaN layer as a response parameter to analyze the experiments using STATGRAPHICS Plus by manugistics.

To assess the influence of the input parameters on the $\mathrm{Al}$ incorporation, a Pareto chart was calculated by the software. Following the Pareto principle, which states that a minority of input produces the majority of results, this chart visualizes the relative significance of the input variables. The maximum order effect to be recognized by the software was set to 2. Due to that, not just the two parameters $\mathrm{V} / \mathrm{III}$ and $\mathrm{Al} / \mathrm{MO}$ were considered, but also their products $(\mathrm{V} / \mathrm{III})^{2},(\mathrm{Al} / \mathrm{MO})^{2}$ and $(\mathrm{V} / \mathrm{III}) \cdot(\mathrm{Al} / \mathrm{MO})$. The influence of the simple $\mathrm{V} / \mathrm{III}$ ratio on the $\mathrm{Al}$ incorporation was found to be so marginal, that it was excluded as an analysis factor. For the set of experiments that was prepared within the scope of this work, the $\mathrm{Al} / \mathrm{MO}$ parameter by far was the most vital one. Yet, any exclusion of one or several of the quadratic parameters lead to a poorer fitting of the estimated response surface, which will be discussed below, to the experimental points.

Using the four significant parameters found with the help of the Pareto chart, an estimated response surface was generated. Figure 3 shows the resulting graph. The surface plane is bent due to the second order effects applied to the fitting. If only linear terms were investigated, the surface would be plane, but it was found that this leads to a poorer agreement of the generated graph to the experimentally obtained results. It has to be noted that the outer areas, especially for high V/III and Al/MO ratios are extrapolated.

For an $\mathrm{Al} / \mathrm{MO}$ ratio of 0.4 , the $\mathrm{Al}$ incorporation at first slightly decreases with an increasing $\mathrm{V} / \mathrm{III}$ ratio and becomes constant for $\mathrm{V} / \mathrm{III}>700$. At higher values of $\mathrm{Al} / \mathrm{MO}$, an inversion of this effect is visible, thus that the $\mathrm{Al}$ incorporation goes up for higher $\mathrm{V} / \mathrm{III}$ rates.

A remarkable effect that becomes apparent from the response surface in Figure 3 is the interaction of the two input parameters. For low V/III ratios, the tunability of the Al content in the deposited AlGaN layer by a variation of the $\mathrm{Al} / \mathrm{MO}$ rate is small. Only for higher $\mathrm{V} / \mathrm{III}$ ratios, the $\mathrm{x}$ value for $\mathrm{Al}_{x} \mathrm{Ga}_{(1-x)} \mathrm{N}$ can be adjusted in a wide range. While for small $\mathrm{V} / \mathrm{III}$ rates the gradient of the response surface towards increasing $\mathrm{Al} / \mathrm{MO}$ ratios is rather small, for high V/III ratios a steep rise of the graph can be observed. To make this more clear, Figure 4 shows the aluminium content versus the V/III ratio for two different, constant $\mathrm{Al} / \mathrm{MO}$ rates. By changing $\mathrm{Al} / \mathrm{MO}$ and $\mathrm{V} / \mathrm{III}$, each point between the two curves is reachable. For V/III $=200$, only $\mathrm{x}$ values from $55 \%$ to about $60 \%$ can be reached, while for $\mathrm{V} / \mathrm{III}=900$ this range is spanned from $28 \%$ to $87 \%$.

Of course, for all these considerations, it has to be taken into account that the positions of the experimentally obtained points are mostly located around the center of the grid in Figure 3. Because of this, the outer areas are subject to an inaccuracy caused by the extrapolation. Especially the sector for high V/III and high Al/MO 
ratios, which exhibits a steep slope in $\mathrm{Al}$ incorporation, so far lacks verification by further experiments. Therefore an interpretation of that portion is uncertain. Despite of this, the discussed effect of an increase in the Al content for increasing V/III ratios already becomes visible in regions, where experimental results support the gradient of the response surface.

From experiments with lower $\mathrm{Al} / \mathrm{MO}$ fractions it is known that the $\mathrm{Al}$ incorporation decreases for rising $\mathrm{V} / \mathrm{III}$ rates, which conforms with the behavior that can be observed for $\mathrm{Al} / \mathrm{MO}=0.4$. This is usually explained by more pre-reactions taking place if there is more ammonia in the reactor. Thereby, the aluminium which is

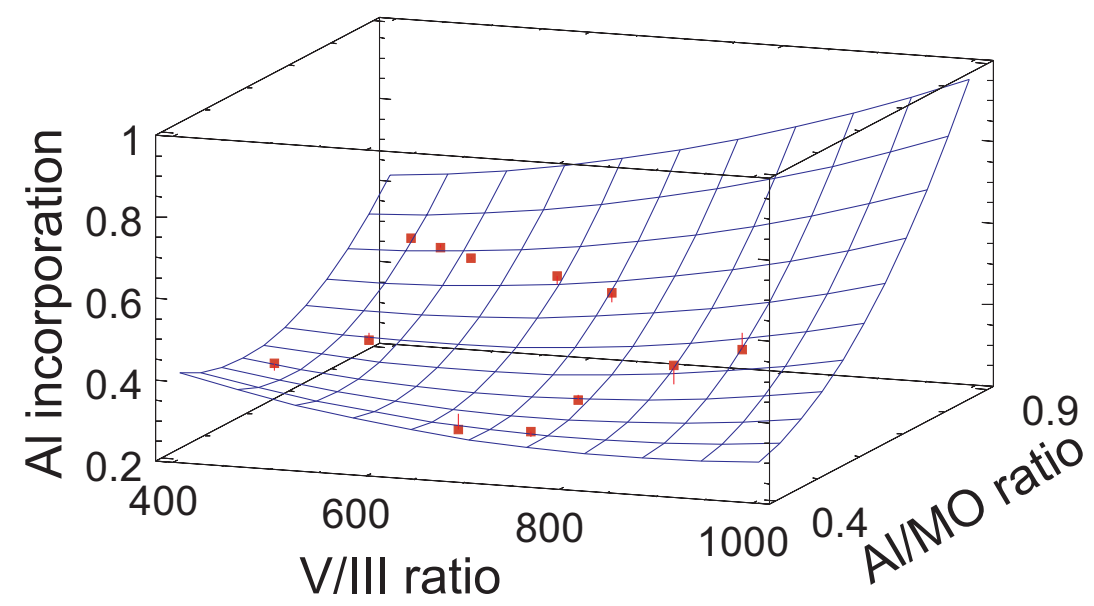

Figure 3. Estimated response surface for the $\mathrm{Al}$ incorporation with $\mathrm{V} / \mathrm{III}$ and $\mathrm{Al} / \mathrm{MO}$ ratios as input parameters including experimentally obtained points. For high V/III and $\mathrm{Al} / \mathrm{MO}$ ratios the surface is extrapolated.

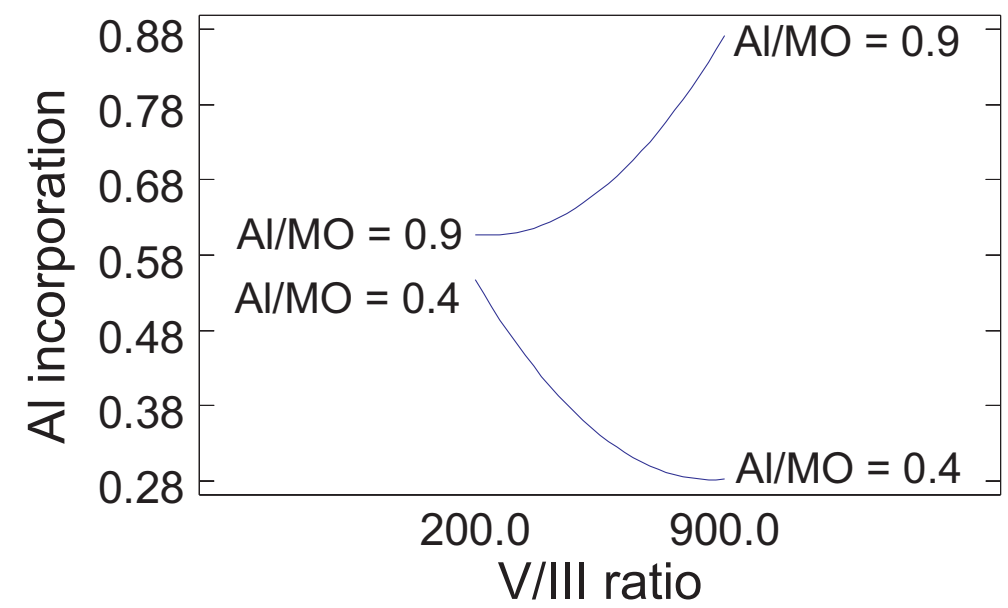

Figure 4. Al incorporation versus V/III ratio for two constant $\mathrm{Al} / \mathrm{MO}$ ratios. 
available to the crystalline growth on the surface is reduced. For higher $\mathrm{Al} / \mathrm{MO}$ values, this effect seems to be superposed and negated by another phenomenon.

A possible explanation for this might be the design of the inlet portion of the reactor in combination with the difference in thermal conductivity of hydrogen and ammonia. For a better understanding, the layout of the inlet is shown in Figure 5. The gas inlet is designed thus that a separation plate isolates the group III and group V

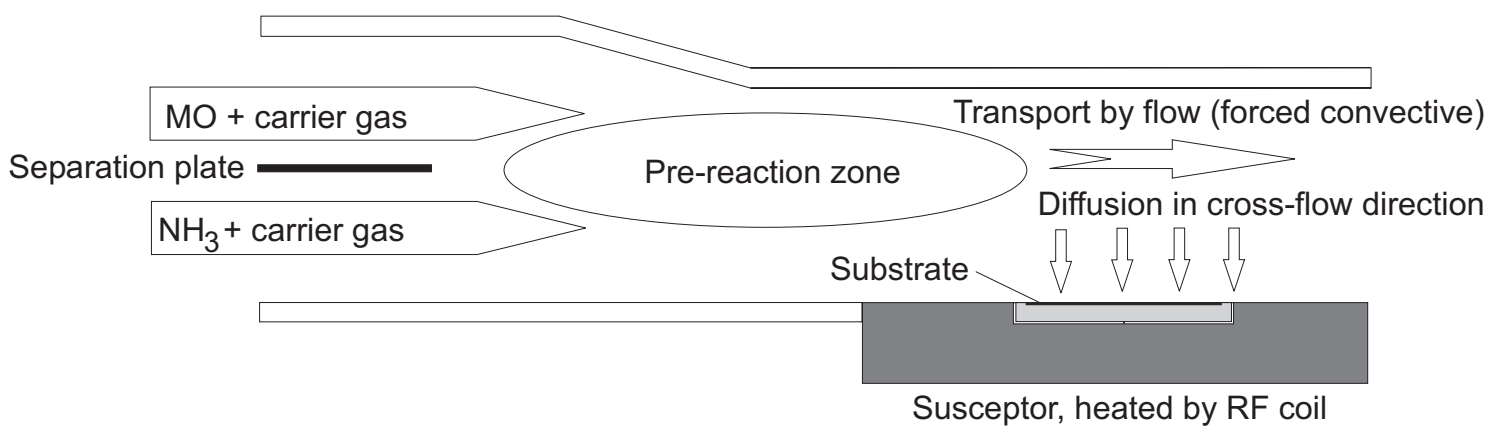

Figure 5. Inlet portion of the reactor.

precursors from each other such that the group III precursors are let into the reactor above and ammonia below the plate. For both material groups, hydrogen was used as a carrier gas. After passing the separation plate, the precursors are not isolated from each other any longer. The main material transport, which is forced by the gas flow, is parallel to the substrate. The precursors move from the cooler inlet area to the hot area above the susceptor while group III precursors diffuse through the hydride and carrier gas flow towards the substrate. During this mixing process of the precursors, pre-reactions in the gas phase start to take place. While these chemical reactions among TMGa and $\mathrm{NH}_{3}$ are reversible, the products from TMAl and ammonia form stable clusters that are carried to the exhaust by the gas stream. ${ }^{9}$ Therefore, $\mathrm{Al}$ atoms involved in these reactions are lost for the epitaxial process on the substrate. This results in a characteristic profile for available aluminium atoms over the susceptor position which first rises steeply. This initial increase can be attributed to the reaction rate of the TMAl dissociation as well as to the fact that the speed of this chemical reaction is temperaturedependent and the TMAl moves towards hotter areas inside the reactor. After the formation of a maximum for the available Al, a depletion occurs which is caused by the material loss through the pre-reactions as well as by depositions on the susceptor and the reactor walls.

Because of the significant dependence of this process on temperature, the reactions of TMAl and $\mathrm{NH}_{3}$ are closely coupled to the temperature profile inside the reactor. This temperature profile in turn depends on the thermal conductivity of the gas phase inside the reactor. Since the thermal conductivity of ammonia is less than the one of hydrogen by factor 7.6, the heat conduction from the hot susceptor towards the reactor inlet is decreased. This leads to the formation of a cooler, finger-shaped zone after the separation plate, the so-called 'cold finger'. The formation and the influence of the cold finger in regards to the carrier gases $\mathrm{H}_{2}$ and $\mathrm{N}_{2}$, that have an almost similar difference in thermal conductivity as $\mathrm{H}_{2}$ and ammonia, were investigated in. ${ }^{10}$ The temperature profiles that were found by Dauelsberg et al. for hydrogen and nitrogen showed significant differences, especially around the inlet area of the reactor. The cold finger in the nitrogen atmosphere reached deeply into the reactor, almost up to the position of the substrate.

The assumption is that by increasing the ammonia flow, a cold-finger effect arises as well, which leads to a shift of the $\mathrm{Al}$ depletion profile towards the substrate and thus to a later onset of this reaction. Therefore, the available aluminium above the substrate would be increased by a higher $\mathrm{NH}_{3}$ flow.

Due to the fact that a high V/III ratio does not necessarily correspond to a high ammonia flow, Figure 6 shows the absolute ammonia flow and the $\mathrm{Al} / \mathrm{Ga}$ ratio as input parameters to verify the above assumption. A rising $\mathrm{Al}$ content of the $\mathrm{AlGaN}$ layer is clearly visible for constant, high $\mathrm{Al} / \mathrm{Ga}$ ratios and an increasing $\mathrm{NH}_{3}$ flow. 
This behavior substantiates the thesis that the ammonia flow influences the Al incorporation into the AlGaN. For lower $\mathrm{Al} / \mathrm{Ga}$ rates this effect becomes less until it inverts into a reduction of the $\mathrm{Al}$ mole fraction for higher ammonia flows. This complies with the inversion observed in Figure 3.

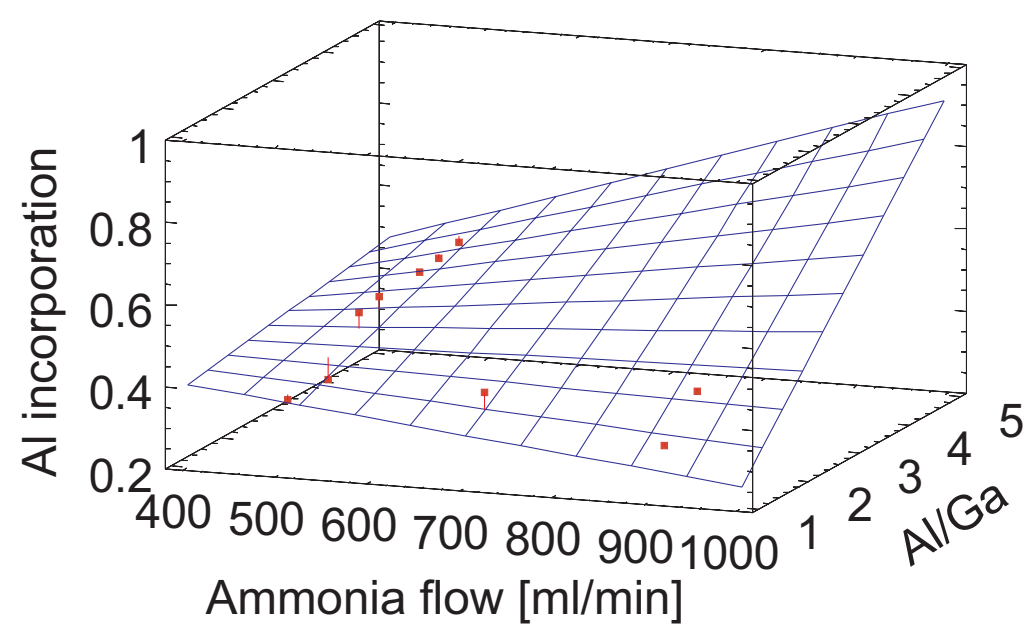

Figure 6. Estimated response surface for the $\mathrm{Al}$ incorporation with $\mathrm{NH}_{3}$ flow and $\mathrm{Al} / \mathrm{Ga}$ ratio as input parameters including experimentally obtained points. For high $\mathrm{NH}_{3}$ flows and high $\mathrm{Al} / \mathrm{Ga}$ ratios the surface is extrapolated.

To assess the quality of the estimated response surface in Figure 3, Figure 7 shows the experimentally observed $\mathrm{Al}$ contents versus the ones predicted by the applied fitting. The results of the twelve experiments taken as basis for this study are marked by the small squares, the diagonal line represents zero deviation between the observed and fitted values. With the highest deviation being 4.7 percentage points, the result is still tolerable and an average deviation of 2.2 percentage points is sufficiently low. Within the tolerance of the transmission measurements, the agreement of observed and predicted results is satisfying.

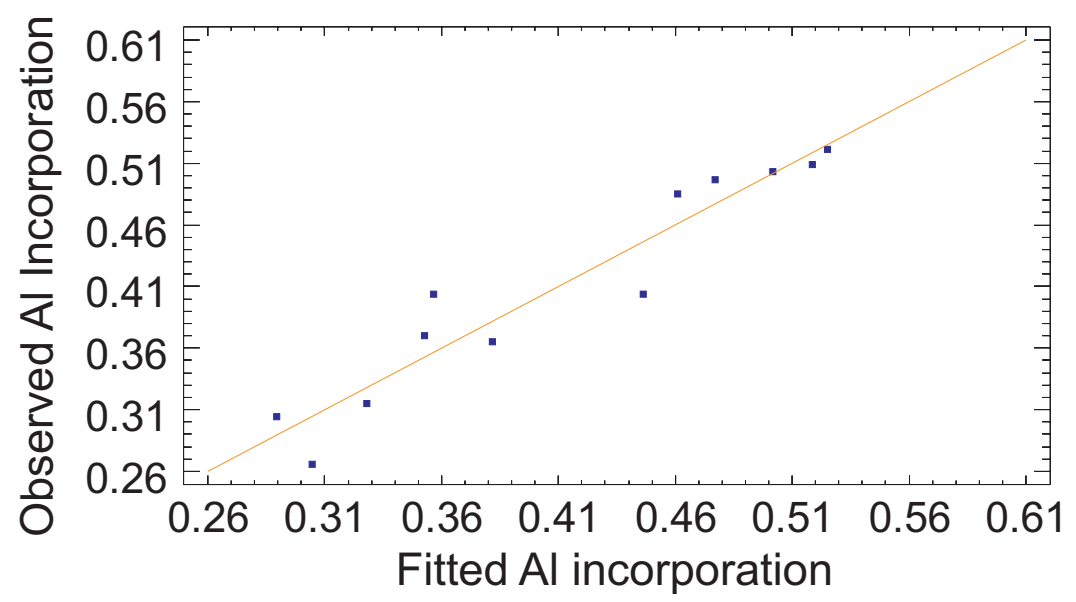

Figure 7. Observed versus fitted $\mathrm{Al}$ incorporation. 


\section{SUMMARY AND CONCLUSIONS}

To investigate the influence of the process parameters $\mathrm{V} / \mathrm{III}$ and $\mathrm{Al} / \mathrm{MO}$ on the aluminium incorporation into AlGaN layers, twelve samples with varying parameters were taken as basis for this study. The $\mathrm{Al}$ contents of the $\mathrm{AlGaN}$ layers were determined by analyzing the spectra of transmission measurements. The cut-off frequencies were transformed into bandgap energies, which were afterwards employed to calculate the $\mathrm{x}$ value of $\mathrm{Al}_{x} \mathrm{Ga}_{(1-x)} \mathrm{N}$. For the evaluation of the experimental results, the software STATGRAPHICS plus was used, with the help of which the relevance of process parameters could be assessed. Furthermore, a response surface map was generated, using the $\mathrm{V} / \mathrm{III}$ and $\mathrm{Al} / \mathrm{MO}$ ratios as input and the $\mathrm{Al}$ content $\mathrm{x}$ as response variable.

The response surface exhibited a decreasing $\mathrm{Al}$ incorporation for increasing $\mathrm{V} / \mathrm{III}$ ratios at lower $\mathrm{Al} / \mathrm{MO}$ ratios. This result was expected due to experiences from former experiments, where this effect was ascribed to more pre-reactions between $\mathrm{TMAl}$ and $\mathrm{NH}_{3}$ at high $\mathrm{V} / \mathrm{III}$ values. An inversion of this phenomenon was observed for higher $\mathrm{Al} / \mathrm{MO}$ fractions, at which the impact of pre-reactions seemed to be overcompensated by another effect. As a possible explanation, the influence of the smaller thermal conductivity of ammonia compared to hydrogen was suggested. An increase of ammonia flow might lead to the formation of a so-called 'cold finger' in the vapor phase, resulting in a shift of the TMAl depletion profile towards the substrate. This shift in turn changes the quantity of aluminium which is available for the epitaxial growth on the substrate.

To verify this assumption, further experiments with increased ammonia flows and constant $\mathrm{Al} / \mathrm{Ga}$ ratio are recommended. Additionally, experiments at high $\mathrm{V} / \mathrm{III}$ and $\mathrm{Al} / \mathrm{MO}$ values should be conducted, since this area of the response surface map is currently subject to extensive extrapolation.

\section{REFERENCES}

1. H. X. Jiang and J. Y. Lin, "AlGaN and InAlGaN alloys - epitaxial growth, optical and electrical properties, and applications," Opto-Electronics Review 10, pp. 271-286, 2002.

2. N. Biyikli, T. Kartaloglu, O. Aytur, I. Kimukin, and E. Ozbay, "High-performance solar-blind AlGaN Schottky photodiodes," Internet J. Nitride Semicond. Res. 8, p. 2, 2003.

3. M. Razeghi and A. Rogalski, "Semiconductor ultraviolet detectors," J. Appl. Phys. 79, p. 7433, 1996.

4. N. Biyikli, O. Aytur, I. Kimukin, T. Tut, and E. Ozbay, "Solar-blind AlGaN-based Schottky photodiodes with low noise and high detectivity," Appl. Phys. Lett. 81, p. 3272, 2002.

5. V. Adivaharan, G. Simin, G. Tamulaitis, R. Srinivasan, J. Yang, M. A. Khan, M. S. Shur, and R. Gaska, "Indium-silicon co-doping of high-aluminium-content AlGaN for solar blind photodetectors," Appl. Phys. Lett. 79, p. 1903, 2001.

6. N. Biyikli, I. Kimukin, T. Kartaloglu, O. Aytur, and E. Ozbay, "High-speed solar-blind photodetectors with indium-tin-oxide Schottky contacts," Appl. Phys. Lett. 82, p. 2344, 2003.

7. I.-S. Seo, S.-J. Lee, S.-H. Jang, J.-M. Yeon, J.-Y. Leem, Y.-J. Park, and C.-R. Lee, "The role of AlN buffer layer in $\mathrm{Al}_{x} \mathrm{Ga}_{1-x} \mathrm{~N} / \mathrm{GaN}$ heterostructures with $\mathrm{x}$ from 0.35 to 0.5 grown on sapphire (0001)," J. Cryst. Growth 241, pp. 297-303, 2002.

8. I. Vurgaftman, J. R. Meyer, and L. R. Ram-Mohan, "Band parameters for III-V compound semiconductors and their alloys," J. Appl. Phys 89(11), pp. 5815-5875, 2001.

9. T. G. Mihopoulos, V. Gupta, and K. F. Jensen, "A reaction transport model for AlGaN MOVPE growth," J. Cryst. Growth 195, pp. 733-739, 1998.

10. M. Dauelsberg, H. Hardtdegen, L. Kadinski, A. Kaluza, and P. Kaufmann, "Modeling and experimental verification of deposition behavior during AlGaAs growth: a comparison for the carrier gases $\mathrm{N}_{2}$ and $\mathrm{H}_{2}$," J. Cryst. Growth 223, pp. 21-28, 2001. 